\title{
Applications of Magnesium and its Alloys: A Review
}

\author{
Jovan Tan ${ }^{1}$ and Seeram Ramakrishna ${ }^{1, *}$ \\ 1 Centre for Nanotechnology and Sustainability, Department of Mechanical Engineering, National University \\ of Singapore, Singapore 117575; \\ * Correspondence: seeram@nus.edu.sg
}

\begin{abstract}
Magnesium is a promising material. It has a remarkable mix of mechanical and biomedical properties that made it suitable for a vast range of applications. With alloying, many of these inherent properties can be further improved. Today, it is primarily used in the automotive, aerospace, and medical industry. However, magnesium has its own set of drawbacks which the industry and research community are actively addressing. Magnesium's rapid corrosion is its most significant drawback, and it dramatically impeded magnesium's growth and expansion into other applications. This article will review both the engineering and biomedical aspects and applications for magnesium and its alloys. It will also elaborate on the challenges the material faces, how they can be overcome, and its outlook.
\end{abstract}

Keywords: Materials; Engineering Materials; Biomaterials; Magnesium; Magnesium Alloys; Properties; Applications

\section{Introduction}

As an alkaline earth metal, magnesium is shiny and silvery-white in appearance. It is also highly reactive and never found free in nature [1] with terrestrial and cosmic abundance [2]. It exists as a chemical compound until Joseph Black (in 1754), with prior contributions from Friedrich Hoffman (in 1729), recognized it as an element [3]. Even though Humphry Davy discovered the first magnesium metal in 1808 [1, 3-7], the first pure magnesium was only produced by Antoine-Alexander Bussy in 1828 [3, 5].

\subsection{Production Techniques}

There are two basic methods of producing magnesium - (a) the electrolysis of fused anhydrous magnesium chloride and (b) metallothermic reduction of magnesium oxide by ferrosilicon [8]. Electrolysis is a two-step approach. It involves the hydrometallurgical preparation of the feedstock (dehydrated magnesium chloride), followed by feeding it directly through electrolytic cells [4]. Michael Faraday first discovered the core principles of producing magnesium metal with this method in 1833 [5].

In 1852, Robert Bunsen improved on Faraday's process to achieve permanent separation of chlorine and magnesium, and that tweak in process kickstarted the commercialization of magnesium [7]. Preventing the recombination of chlorine and magnesium was critical to Robert Bunsen's success as anhydrous magnesium chloride is hygroscopic. It can lead to undesirable oxides and oxychlorides forming during direct dehydration [8]. Presently, it is still a technological challenge to produce anhydrous magnesium chloride with minimal or, ideally, no oxychlorides [9].

The second method of producing magnesium metal is with heat. When the thermal reduction process was first introduced in the 1920s [9], it was touted to be the eventual replacement of electrolysis production. Unlike electrolysis, intense heat in the thermal reduction process eliminates the need for an elaborate feedstock preparation [7]. The Pidgeon and Magnetherm processes are the main thermal routes. They are also batched process [8] that uses the same basic chemistry [4]. In the Pidgeon process, dolomite and 
ferrosilicon are formed into briquettes with an externally heated retort to attain magnesium vapors.

On the other hand, the Magnetherm process calcines a mixture of dolomite, ferrosilicon, and alumina to achieve the same by-product. Magnesium vapors from both routes are cooled and condensed separately before being extracted [4]. A typical production process using the Bunsen's electrolytic method and the Pidgeon method is illustrated in Figure 1.

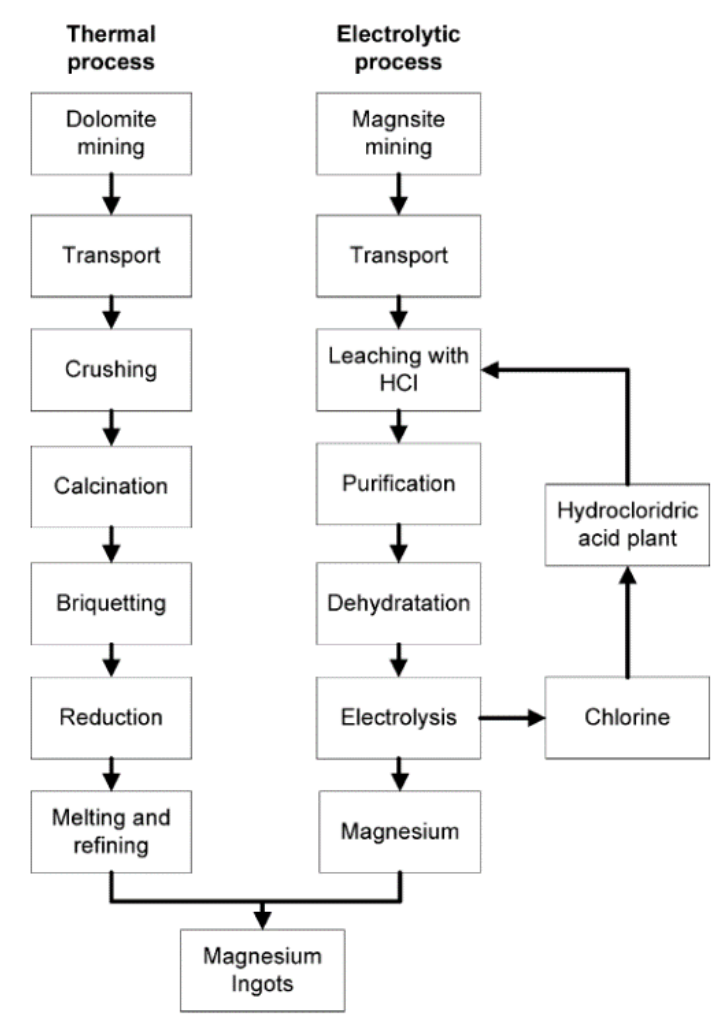

Figure 1. Process flowchart of primary magnesium production via thermal and electrolytic process. Reproduced with permission from Cherubini, F., et al., LCA of magnesium production; published by Elsevier, 2008 [10]

Melting and casting magnesium alloys in a vacuum-assisted inert atmosphere is the preferred manufacturing process to fabricate magnesium alloys [11]. This process is preferred as magnesium solidifies better than other cast metals and that a chemically inactive environment can prevent any contamination from reactive gases.

\section{Magnesium and its Alloys as an Engineering Material}

\subsection{Engineering Properties}

Magnesium is the lightest engineering metal. It has a low density of $1.74 \mathrm{~g} / \mathrm{cm} 3$ [12], and it exhibits a higher strength-to-weight ratio and better ductility and castability than aluminum and steel [13]. Compared to other metals and polymeric materials, magnesium presents no toxicity hazard [2] and performs better in thermal and electrical conductivity, vibration and shock absorption, and damping capacity [14]. Magnesium also possesses good machinability and can be shaped with any established methods [2].

Magnesium's notable weakness is in its proneness to corrosion. It also corrodes quickly under two conditions - (a) when the alloy is constructed with specific metallic impurities or (b) exposure to aggressive electrolyte species. Coating technologies have since been developed and utilized to overcome this weakness, e.g., electrochemical plating, conversion coatings, and anodizing [15].

With a minimum purity of 99.8 percent, pure magnesium is available commercially [16], and it is suitable for most applications [8]. Pure magnesium is ideal for metallurgical 
and chemical uses but not for engineering and structural purposes [12]. It must be alloyed for engineering and structural applications to strengthen its weaker properties without sacrificing its key features [7]. Solid solution strengthening and second phase strengthening are commonly used to reinforce magnesium alloys [17].

The alloying constituents and its chemical compositions can influence magnesium alloys' enhanced physical properties. The most common and preferred alloying elements are aluminum and zinc, as they are favorable, economical, and highly soluble in magnesium [18]. Aluminum can be used to improve the alloy's strength, hardness, and melting range. Used together with zinc, it can further enhance the alloy's strength at room temperature. Adding zinc, by itself, can increase alloy fluidity in casting. When zinc, together with magnesium alloys, is mixed with impurities like nickel and iron, it can strengthen the alloy's resistance to corrosion [12].

In addition to traditional alloying, there have been, in recent years, significant research progress in magnesium alloy-based nanocomposites - where magnesium and its alloys are further reinforced with nano-sized particles [19]. The characteristics of these magnesium alloy-based nanocomposites are influenced by both the alloying constituents and the reinforced nanoparticles [20]. This domain's heightened research interest stems from the revelation that reinforcements with nanoparticles can improve magnesium's strength and ductility without any adverse effect [19]. While there may be limited commercial applications today, this discovery has posed magnesium alloy-based nanocomposites' to be a candidate for replacing traditionally alloyed magnesium in both engineering and biomedical applications [20].

To identify magnesium alloys and their principal alloy composition, one can refer to the alphanumeric designation system established by the American Society of Testing and Materials (ASTM), as well as relevant international and European standards. More diverse combinations of magnesium and its constituents and its resultant effect have been discussed in great length and summarized in ASM's 2017 book [12]. Selected mechanical properties between magnesium, its common alternatives, and biological tissues are also compared in Table 1 below.

Table 1. Selected Mechanical Properties

\begin{tabular}{|c|c|c|c|c|c|}
\hline Materials & $\begin{array}{r}\text { Density } \\
\left(\mathrm{g} \mathrm{cm}^{3}\right)\end{array}$ & $\begin{array}{l}\text { Compressive } \\
\text { Strength (MPa) }\end{array}$ & $\begin{array}{c}\text { Tensile Strength } \\
\text { (MPa) }\end{array}$ & $\begin{array}{l}\text { Elastic Modulus } \\
\qquad(\mathrm{GPa})\end{array}$ & Reference \\
\hline \multicolumn{6}{|l|}{ Magnesium } \\
\hline Pure Magnesium & 1.74 & $20-115$ & $90-190$ & 45 & [21] \\
\hline AZ31 Alloy (Extruded) & 1.78 & $83-97$ & $241-260$ & 45 & [21] \\
\hline AZ91D Alloy (Die Cast) & 1.81 & 160 & 230 & 45 & [21] \\
\hline \multicolumn{6}{|l|}{ Alternative Metals } \\
\hline Aluminum Alloys & 2.7 & - & $170-560$ & 70 & {$[22,23]$} \\
\hline Stainless Steel & $7.9-8.1$ & - & $480-620$ & $189-205$ & {$[21,24]$} \\
\hline Cobalt-Chrome Alloys & $7.8-9.2$ & - & $450-960$ & $195-230$ & {$[21,24]$} \\
\hline Titanium Alloys & $4.4-4.5$ & - & $550-985$ & $100-125$ & {$[21,24]$} \\
\hline \multicolumn{6}{|l|}{ Biological Tissues } \\
\hline Arterial Wall & - & - & $0.5-1.72$ & 0.001 & {$[21,25]$} \\
\hline Skin & - & - & $2.5-16$ & $0.006-0.04$ & {$[25]$} \\
\hline Cancellous Bone & $1-1.4$ & $1.5-9.3$ & $1.5-38$ & $0.01-1.57$ & {$[21,25]$} \\
\hline Cortical Bone & $1.8-2$ & $\begin{array}{l}160 \text { Transverse } \\
240 \text { Longitudinal }\end{array}$ & $\begin{array}{c}35 \text { Transverse } \\
283 \text { Longitudinal }\end{array}$ & $5-23$ & {$[21,25,26]$} \\
\hline
\end{tabular}




\subsection{Engineering Applications}

Early applications for magnesium include fabricating incendiary bombs, pyrotechnics, and flash for photography [5]. These military applications led magnesium to play a considerable role in World War 1 and World War 2. In World War 2, magnesium was also used to construct military aircraft and its components [27], and that paved the way for magnesium to become a mainstay in the civil aerospace industry. There are environmental and economic benefits of using magnesium in constructing aircraft. Using a lighter metal like magnesium in place of heavier metals can improve the aircraft's fuel efficiency and reduce emissions. This translates to savings on fuel and a lower operational cost. Further, magnesium's excellent castability, machinability, and ductility make it advantageous over other conventional metallic materials. However, modern aviation has restrictions on the use of magnesium alloys due to flammability and corrosion concerns. Despite significant improvements since the restrictions were first imposed, magnesium is still found in engine- and transmission-related castings and landing gears only and not in external or structural applications [28].

For similar reasons to the aerospace industry, magnesium was also adopted by the automotive industry for its "in-use" benefits. The automotive industry came under increased pressure by authorities and the wider community to reduce its emissions and pursue a more sustainable pattern of growth. As magnesium and its alloys can reduce the vehicle's weight, provide energy savings, and limit environmental impact without compromising its overall strength and functions [13], it fueled adoption despite having a higher price point over other conventional metallic materials like aluminum.

Beyond engineering applications, magnesium, by itself or as an alloy, can also be found in a wide range of applications from medical and metallurgical to chemical and pyrotechnic [12]. The heightened interest and possibilities for this material have encouraged more research efforts in discovering more efficient ways of producing magnesium metal and its alloys and new and extended applications [7].

\section{Magnesium and its Alloys as a Biomaterial}

The earliest medical use for magnesium can be traced back to 1695 when Nehemiah Grew extracted naturally occurring magnesium sulfate from a spring in Epsom town of southern England [5]. In 1878, Edward C. Huse used magnesium wires as blood vessel ligatures [3], and this was the first reported use of magnesium metal for medical purposes. Since then, several notable experiments have been conducted to assess magnesium's suitability as a biomaterial.

Erwin Payr was one such influential pioneer who extended magnesium's prospects as a biomaterial into various surgical areas and further hypothesized the factors leading to magnesium's corrosion in vivo [6]. Another early pioneer is Albin Lambotte and his assistant, Jean Verbrugge, who further extended it to orthopedic applications and concluded that magnesium implants are not toxic or irritant [29]. Other early experimental application also includes fabricating tubes, plates, wires, sheets, and screws out of pure magnesium, and they were tested on both humans and animals [6].

The first use of Magnesium alloy in the medical field was only reported much later, in 1948, by Troitskii and Tsitrin using magnesium cadmium to treat cases of pseudarthrosis [29]. Following Troitskii and Tsitrin's experimental application, there have been no reported clinical studies of magnesium-based orthopedic implants [30], while other clinical studies were conducted on a small scale [29]. An extensive review of magnesium's rich history as a biomaterial has been documented by Frank Witte [6].

\subsection{Biocompatibility, Biodegradability, Bioabsorbability}

There is growing literature on magnesium and its alloys as a biomaterial, especially as a temporary implant. The strong interest stems from magnesium's remarkable engineering properties and its natural occurrence in the human body. Magnesium is the second most abundant and essential intracellular cation [5]. It is an essential mineral that supports physiological functions in the human body, including the structural stabilization 
of proteins, nucleic acids, and cell membranes and the promotion of specific structural or catalytic activities of proteins, enzymes, or ribozymes [1]. Moreover, magnesium is also non-toxic and non-irritant. It is known to promote tissue healing in the human body and can be excreted through urine or feces [30]. Magnesium is also primarily found inside cells or bones, where it is known to support osteoinductivity [3]. Hence, with these factors combined, magnesium is naturally biocompatible with the human body.

Magnesium's greatest strength lies beyond biocompatibility. It excels in biodegradability and bioabsorbability [24]. It is also bioresorbable and a bioactive material [3]. Often, the body only requires the temporary presence of an implant or device [14] to support its tissue regeneration and restoration of impaired physical functions [17]. If the implant is not removed promptly, it may lead to undesirable responses like chronic physical irritation and inflammatory response, or worse, introduce biotoxicity [31].

When evaluating for use as a temporary implant, biodegradability is of the utmost importance. Ideally, the implant should biodegrade and completely dematerialize after the tissue has healed completely. As the implant degrades, its strength and stiffness should decrease at an inversely proportionate rate to the healing of host tissue and recovery of its load-bearing capacity and mechanical integrity [31]. This inverse relationship can be explained in Figure 2. Additionally, the biodegradation process should also occur without any adverse effect on the human body. Unlike traditional metallic implant materials like stainless steel, cobalt-chromium alloys, and titanium alloys which are bio-inert, Magnesium is both biodegradable and bioabsorbable. This eliminates the need for followup surgery to remove the implant after the impaired physical functions have been restored [24].

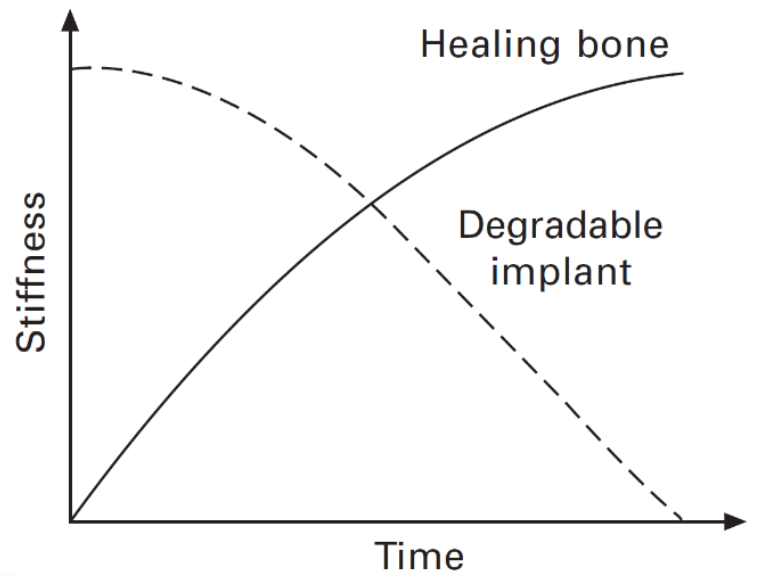

Figure 2. Stiffness-Time inverse relationship between degradable implants and healing bone. Reproduced with permission from Witte, F., et al., Magnesium (Mg) corrosion: a challenging concept for degradable implants; published by Woodhead Publishing, 2011 [32]

\subsection{Mechanical Functionality}

As previously discussed, magnesium has outstanding engineering and mechanical properties, especially its light weight and density. However, as a biomaterial, and in comparison, with its bio-inert counterparts, magnesium possesses several mechanical limitations which impeded its widespread adoption. Metallic implants are preferred over other biomaterials (like ceramics or polymers) for their superior load-bearing capabilities, corrosion behavior, and fracture toughness [31]. Despite being a metallic implant material, magnesium exhibits weaker abilities in the above areas, limiting its biomaterial applications [17].

Nonetheless, magnesium alloys have a lower elastic modulus than their bio-inert counterparts (refer to Table 1), which is advantageous as a biomaterial. A higher elastic modulus is directly proportionate to the increasing stiffness of the materials, and an overly stiff implant can cause stress shielding, which hinders the healing process. In more severe 
cases, it may even lead to bone loss and possibly a secondary bone fracture [30, 31]. As magnesium's elastic modulus is closer to the stiffness of natural bone, it is preferred [31].

\subsection{Corrosion}

Magnesium's ability to biodegrade is its greatest strength, while the speed at which it degrades is its greatest weakness. Magnesium degrades rapidly in a physiological environment. Such accelerated degradation can compromise the mechanical integrity and strength of its respective applications. Besides, it can result in possible deleterious and consequences [3] such as premature failure of the implant [24], interference with the healing process, and in extreme cases - death [33]. Corrosion is a form of biodegradation.

With limited research and technologies in its early days, surgeons faced great difficulty managing magnesium corrosion in vivo. As such, they preferred the use of corrosion-resistant V2A steel in place of magnesium, and that waned interest in magnesium as a prospective biomaterial [6]. Despite significant advances today, managing magnesium corrosion is still a major technological challenge [34].

The types of magnesium corrosion can be classified into general/uniform or localized. Predominately, magnesium can be exposed to galvanic corrosion, pitting corrosion, filiform corrosion, intergranular corrosion (IGC), exfoliation corrosion (EFC), crevice corrosion, stress corrosion cracking (SCC), corrosion fatigue (CF), and erosion-corrosion [35].

Magnesium corrosion in vivo accelerates in the presence of chloride ions, which can be found in human body fluid or blood plasma [33]. Magnesium corrodes in an aqueous environment via an electrochemical reaction to produce hydroxide and hydrogen gas [32]. The produced hydroxide layer quickly gets converted away into highly soluble magnesium chloride, and this reinforcing process loop hastens the rate of magnesium's corrosion [34].

Extensive literature has identified magnesium's rapid degradation to contribute to hydrogen evolution and alkalization [14]. Hydrogen evolution refers to the production of subcutaneous hydrogen bubbles adjacent to the implants [33]. The rate at which these hydrogen bubbles are produced is directly correlated to the corrosion rate of magnesium [36]. When hydrogen is produced faster than it can be absorbed, it will create a balloon effect [14] which can tear and destroy the tissues and their layers as it gets separated. The destruction of tissues can delay the healing process, and in extreme cases, it can be fatal if the balloon hydrogen bubbles get too large and disrupt the bloodstream [33].

Local alkalization around a rapidly corroding magnesium implant is also a primary medical concern. While the human body can manage slight fluctuations in $\mathrm{pH}$ level, a greater alkaline concentration can create an adverse physiological reaction. If the in vivo $\mathrm{pH}$ value of the localized region exceeds 7.8, it can lead to alkaline poisoning [33].

A review of the literature suggests three key strategies to overcome magnesium's corrosive behaviors. They are purification, alloying, and surface modification. These strategies employ the same principle of slowing the biodegradation process. By incorporating them, it can reduce the speed of hydrogen accumulation and localized alkalinization. It will also provide room for the human body to adjust and deal with the magnesium implants [33]. While purifying magnesium is an option to reduce its corrosion rate materially, it will produce a pure magnesium metal with several mechanical limitations, as discussed above, and render it unsuitable for most medical applications [31].

Instead, like how pure magnesium is alloyed for engineering and structural applications, alloying is widely used to improve magnesium's mechanical and corrosive performance as a biomaterial. Many variables can affect the alloy's mechanical and corrosive performance and its implications to the human body [33]. These variables include the alloying elements, their level of purity, their microstructure, and how the materials are processed and alloyed $[3,36]$. Therefore, a careful and holistic assessment of the alloying element is critical. It must be biocompatible, not known to produce any biotoxins or avoidable inflammatory response, and optimized for its respective biomedical applications [14, 20, 31]. Aluminum $(\mathrm{Al})$, calcium $(\mathrm{Ca})$, zinc $(\mathrm{Zn})$, zirconium $(\mathrm{Zr})$, strontium $(\mathrm{Sr})$ are commonly used as alloying elements [29]. Rare earth elements like yttrium $(Y)$, gadolinium 
$(\mathrm{Gd})$, lanthanum (La), and dysprosium (Dy) are also considered even though their biocompatibility remains a question [3].

Presently, alloying, by itself, seems to be limited in clinical practice as its ability to improve corrosion resistance is insignificant [37]. On the other hand, modifying the surface with a coating layer effectively controls the initial degradation of magnesium and its alloys [38]. Compared to alloying, surface modification can retain the material's critical properties while achieving enhanced corrosion resistance and biocompatibility [39].

Taking a step further, current trends suggest combining both methods (coating on alloys) to be widely accepted and adopted. Like alloying, the applied coating should be optimized to its substrate and its intended biomedical purpose. Surface modification methods include micro-arc oxidation (MAO), chemical transformation, electrodeposition, and biomimetic deposition [37]. The main types of coating include polymeric coatings, calcium-phosphate coatings, and graphene coatings [24]. For an in-depth discussion on surface modifications for magnesium and its alloys, one can refer to publications by Mousa et al. [38] and Zeng et al. [35].

\subsection{Anti-Microbial Strategies}

As all medical devices are subjected to microbial colonization and infection [40], effective prevention of bacterial infection is a top priority. Failure to do so can compromise the efficacy of the implant and, in some cases, result in infection persistence, implant failure, and even death of the patients [41]. Often, when an infection occurs, additional surgery and repair of the implant are needed, which adds to the patient's medical burden. Bacterial biofilms are estimated to cause two-thirds of human bacterial infections. It is essentially a densely packed community of microbial cells that are challenging to eradicate when formed. Their resistance to the immune system and antibiotics has been observed [40]. As such, antibiotic-loaded biomaterials and, more recently, stimulus-responsive biomaterials have also been developed to intensify the bacteria-killing process before it attaches to the implant surface [41].

Magnesium's rapid corrosive behavior is a blessing in disguise. Its rapid corrosion increases the concentration of magnesium ions locally, which alters the $\mathrm{pH}$ value and prohibits bacterial activities in vivo [42]. Though recent studies have further confirmed the significant antibacterial effect of magnesium ions on Staphylococcus epidermidis and Escherichia coli (E. coli) [43], it is essential to note that with biofilms, bacteria can withstand external $\mathrm{pH}$ alterations and continue infecting the tissues [40].

Magnesium, by itself, cannot attain excellent antibacterial performance. Therefore, novel magnesium alloys (with alloying elements that possess antibacterial properties like silver, copper, zinc, gallium) and antibacterial coatings are developed [40].

\subsection{Biomaterial Applications}

Magnesium may not be the perfect biomaterial, but the compromise between its merits and weaknesses has paved the way for specific medical applications. Magnesium and its alloys are mainly used for musculoskeletal and cardiovascular applications. Even though they are also used in general and oral applications, the main applications will be the focus of this section. 


\subsubsection{Musculoskeletal and Orthopedic Applications}

Autografting is the yardstick of contemporary bone repair materials. It contains the necessary elements to stimulate new bone growth. However, it is resource-scarce, and it requires secondary surgeries to remove the implant after the impaired physical functions have been restored [44]. As previously discussed, the need for secondary surgeries is also a challenge faced by bio-inert metallic implants, in addition to stress shielding [24].

Hence, the medical community has been actively seeking prospective implant solutions that are biocompatible, biodegradable, and exhibit similar characteristics to the human bone. Novel biomaterials like biodegradable polymers have been investigated for their suitability as they also share properties similar to materials found in the human body [34]. However, biodegradable polymers possess inferior mechanical strength and brittleness to magnesium and its alloys, resulting in surgery failure when employed in loadbearing applications [30]. Further, employing biodegradable polymers is also observed to induce long-term inflammatory responses in peri-implant tissue and discourage osseous ingrowth [30].

Except for its rapid corrosive behavior, magnesium is a more promising biomaterial than biodegradable polymers for bone substitution and scaffolding of bone tissue [29]. While there has been an initial loss of interest in using magnesium as a biomaterial from the medical community [30], in part due to the challenges in managing its overly-active corrosive characteristics [6], interest for clinical applications has since renewed in the recent decade. There have been momentous research and technological advancements in metallurgy that made fabricating magnesium and its alloys with better mechanical and corrosive performance possible [30]. With sustained interest and efforts to continuously improve its properties for clinical use, magnesium and its alloys will be highly desirable as an orthopedic biomaterial. Eventually, it may be an ideal replacement to bio-inert metallic implants in typical musculoskeletal and orthopedic applications like bone substitutes, fixatives, and stabilization devices for fractured bones, ligament and tendon repair, and total hip arthroplasty [30].

\subsubsection{Cardiovascular Applications}

Presently, there are limited applications for magnesium alloys in cardiovascular medicine, as they are mostly experimental or preclinical [45]. Magnesium and its alloys are being investigated for its suitability to replace bio-inert metallic implants in typical cardiovascular therapeutic applications. These include prosthesis implantation and stent insertions like artificial valves, stents, pacemaker cases, and stent grafts [46].

As with any medical applications, metallic implants are preferred over ceramics and polymers for their biocompatibility and superior mechanical properties [47]. Like musculoskeletal and orthopedic applications, its ability to biodegrade is critical. It can reduce the need for risky and expensive surgical operations to remove or replace the metal at each stage of the patient's growth. Specific to cardiovascular medicine, it will reduce the likelihood of thrombogenesis, restenosis, endothelial dysfunction, and other clinical complications [46, 47].

As magnesium-based biodegradable coronary stent implantation is a therapeutic application to coronary heart disease, one of the leading causes of death globally [45-47], it is extensively investigated today. Though it is a promising biomaterial, early in vivo trials have demonstrated mixed clinical outcomes [47].

\section{Outlook}

\subsection{Increasing Demand for Magnesium}

Magnesium's availability and unique blend of properties make it attractive for an extensive range of applications. The global magnesium market is forecasted to grow at a CAGR of $4.9 \%$ and reach 1.6 million metric tons by 2027 , from 1.1 million metric tons in 2020 [48]. China produced 0.9 million metric tons in 2020, which is more than $80 \%$ of the global production [49], and it uses the Pidgeon process to produce primary magnesium metal. 


\subsection{Carbothermic Reduction as a New Production Technique}

The Pidgeon process is notorious for consuming a massive amount of energy per production batch [50] to the extent that Ramakrishnan and Koltun estimated the global warming impact of producing Magnesium metal in China to be $\sim 60 \%$ higher than producing aluminum in China [51]. These led to a search for more efficient and sustainable production technologies. An alternative production route is a carbothermic reduction, where magnesia reacts with carbon to produce magnesium and carbon monoxide vapor.

Though this production method has had large-scale industrial trials in the mid-20th century, it has only garnered more attention in the recent decades as (a) carbon is a cheaper reductant than ferrosilicon, (b) carbon is readily available, and (c) the overall production cost is estimated to be significantly cheaper than the Pidgeon method [52]. Additionally, there is also a growing research interest in solar carbothermic reduction. Recent preliminary studies have concluded the process to consume lesser energy and emit lesser carbon dioxide at 32.3 mega-joules (MJ) of primary energy and 5.31 kilogram $(\mathrm{kg})$ of CO2 per kg magnesium as compared to $181.4 \mathrm{MJ}$ and $15.9 \mathrm{~kg} \mathrm{CO} 2$ in the Pidgeon process [53].

\subsection{D Printing as a New Production Technique}

Additive manufacturing, or 3D printing, is also an emerging production method for magnesium alloys. In general, there has been a growing interest in the 3D printing of metals due to its ability to customizing and optimizing each alloy to suit its respective applications and yield the best possible outcome. An example would be to print the alloy in a more closely aligned configuration to the anatomical geometries of its patient's host tissues [54] to promote more significant cell growth, proliferation, and bone regeneration [55]. This was previously not achievable with traditional manufacturing. Further, as opposed to conventional production methods, biofabrication with additive manufacturing can significantly reduce the technical difficulty and cost of customized production while improving its efficiency [56].

However, investigations on how magnesium alloys can be 3D printed are limited [57] as it is known to come with several challenges. Firstly, it is chemically reactive and flammable. Next, it also has a low vaporization temperature, which increases the difficulty in mixing and printing magnesium alloys with the desired density, strength, biocompatibility, and corrosion behavior [55]. Lastly, the preparation of feedstock is also known to be dangerous as magnesium powders have a high tendency to explode [54]. Today, the two typical additive manufacturing methods to process magnesium alloys are wire arc additive manufacturing (WAAM) and selective laser melting, also known as the powder bed fusion method [57].

\subsection{Recycling Magnesium}

Magnesium is highly recyclable, and recycling magnesium is an additional source of supply to primary production. Today, there are both flux and fluxless technologies to recycle magnesium. Recycled magnesium retains the same chemical, physical, and mechanical characteristics before it was recycled [58]. Additionally, recycling magnesium only consumes $5 \%$ of the energy needed to produce it [7]. Using secondary magnesium also reduces carbon footprint [59] and keeps the material in the circular economy. However, magnesium alloys are only easily recyclable if their alloy composition is consistent and free of impurities [60]. That explains why most recycled magnesium comes from magnesium alloy scraps in the die-casting industry [58]. For magnesium recycling to truly take off, the industry needs to devise a recycling process that is both commercially viable and environmentally sound [60].

\section{Conclusion}

Magnesium's availability and unique blend of properties made it very attractive for engineering and biomedical applications. Alloying magnesium can further modify or enhance its existing properties to make it suitable for even more applications. As an engineering material, magnesium's notable characteristics include its lightweight, specific 
high strength to weight ratio, and superior machinability and castability. These factors enabled magnesium to find its footing in aerospace and automotive applications - where the industry is actively seeking lighter-weight alternatives to harness additional environmental and economic benefits. As a biomaterial, magnesium's notable characteristics include its biocompatibility, biodegradability, and bioabsorbability on top of the engineering properties. It also includes its elastic modulus and innate anti-microbial mechanisms. Hence, magnesium is used mainly in orthopedic and cardiovascular medicine.

While its ability to biodegrade is celebrated, the rate it biodegrades is problematic. It biodegrades rapidly, and as a result, this impeded magnesium's widespread adoption in both engineering and biomaterial applications. Nonetheless, with the ongoing research progress and technological advancements, the mitigation strategies to overcome magnesium's overly rapid degradation are being extensively investigated.

All in all, magnesium is a promising material, and market research has demonstrated its projected increased demand. However, today's primary magnesium is energy-intensive and inefficient to produce, which inspired research in additive manufacturing of magnesium alloys and using solar energy to perform the carbothermic reduction. Recycling magnesium is also an option to keep the supply circular, and there are ongoing investigations to determine the most commercially viable and environmentally sound recycling process.

Author Contributions: J.T.: Conceptualization, methodology, formal analysis, investigation, writing - original draft preparation, S.R.: writing - review and editing, resources, supervision. All authors have read and agreed to the published version of the manuscript.

Funding: This research received no external funding.

Institutional Review Board Statement: Not applicable.

Informed Consent Statement: Not applicable.

Data Availability Statement: Data is contained within the article.

Conflicts of Interest: The authors declare no conflict of interest.

\section{References}

[1] M. A. SHAND, "History of Magnesia," in The Chemistry and Technology of Magnesia: John Wiley \& Sons, Inc., 2006, pp. 1-4.

[2] G. L. Song and A. Atrens, "Corrosion Mechanisms of Magnesium Alloys," Advanced Engineering Materials, vol. 1, no. 1, pp. 11-33, 1999/09/01 1999, doi: 10.1002/(SICI)1527-2648(199909)1:1<11::AID-ADEM11>3.0.CO;2-N.

[3] B. J. C. Luthringer, F. Feyerabend, and R. Willumeit-Römer, "Magnesium-based implants: a mini-review," Magnesium Research, vol. 27, no. 4, pp. 142-154, 2014-10-01 2014, doi: 10.1684/mrh.2015.0375.

[4] U.S. Geological Survey. (2001). 01-341, Magnesium, Its Alloys and Compounds. [Online] Available: https://pubs.usgs.gov/of/2001/of01-341/

[5] J. Durlach, "Overview of Magnesium Research: History and Current Trends," in New Perspectives in Magnesium Research: Springer London, 2006, pp. 3-10.

[6] F. Witte, "The history of biodegradable magnesium implants: A review 岤," Acta Biomaterialia, vol. 6, no. 5, pp. 1680-1692, 2010-05-01 2010, doi: 10.1016/j.actbio.2010.02.028.

[7] F. Czerwinski, "Magnesium and Its Alloys," in Magnesium Injection Molding: Springer US, 2008, pp. 1-79.

[8] I. J. Polmear, "Magnesium alloys and applications," Materials Science and Technology, vol. 10, no. 1, pp. 1-16, 1994-01-01 1994, doi: 10.1179/mst.1994.10.1.1.

[9] G. C. Holywell, "Magnesium: The first quarter millennium," JOM, vol. 57, no. 7, pp. 26-33, 2005-07-01 2005, doi: 10.1007/s11837-005-0248-1.

[10] F. Cherubini, M. Raugei, and S. Ulgiati, "LCA of magnesium production," Resources, Conservation and Recycling, vol. 52, no. 8-9, pp. 1093-1100, 2008-07-01 2008, doi: 10.1016/j.resconrec.2008.05.001. 
[11] A. Kumar, S. Kumar, and N. K. Mukhopadhyay, "Introduction to magnesium alloy processing technology and development of low-cost stir casting process for magnesium alloy and its composites," Journal of Magnesium and Alloys, vol. 6, no. 3, pp. 245-254, 2018-09-01 2018, doi: 10.1016/j.jma.2018.05.006.

[12] C. Moosbrugger and L. Marquard, Engineering properties of magnesium alloys. Materials Park, Ohio: ASM International, 2017, p. 184 pages.

[13] M. K. Kulekci, "Magnesium and its alloys applications in automotive industry," The International Journal of Advanced Manufacturing Technology, vol. 39, no. 9-10, pp. 851-865, 2008-11-01 2008, doi: 10.1007/s00170-007-1279-2.

[14] H. Hornberger, S. Virtanen, and A. R. Boccaccini, "Biomedical coatings on magnesium alloys - A review," Acta Biomaterialia, vol. 8, no. 7, pp. 2442-2455, 2012-07-01 2012, doi: 10.1016/j.actbio.2012.04.012.

[15] J. E. Gray and B. Luan, "Protective coatings on magnesium and its alloys - a critical review," Journal of Alloys and Compounds, vol. 336, no. 1-2, pp. 88-113, 2002-04-01 2002, doi: 10.1016/s0925-8388(01)01899-0.

[16] J.-F. Nie, "Precipitation and Hardening in Magnesium Alloys," Metallurgical and Materials Transactions A, vol. 43, no. 11, pp. 3891-3939, 2012-11-01 2012, doi: 10.1007/s11661-012-1217-2.

[17] J. Chen, L. Tan, X. Yu, I. P. Etim, M. Ibrahim, and K. Yang, "Mechanical properties of magnesium alloys for medical application: A review," Journal of the Mechanical Behavior of Biomedical Materials, vol. 87, pp. 68-79, 2018-11-01 2018, doi: 10.1016/j.jmbbm.2018.07.022.

[18] H. Somekawa, "Effect of Alloying Elements on Fracture Toughness and Ductility in Magnesium Binary Alloys; A Review," MATERIALS TRANSACTIONS, vol. 61, no. 1, pp. 1-13, 2020-01-01 2020, doi: 10.2320/matertrans.mt-m2019185.

[19] M. Gupta and W. L. E. Wong, "Magnesium-based nanocomposites: Lightweight materials of the future," Materials Characterization, vol. 105, pp. 30-46, 2015-07-01 2015, doi: 10.1016/j.matchar.2015.04.015.

[20] S. Tekumalla and M. Gupta, "Processing, Properties and Potential Applications of Magnesium Alloy-Based Nanocomposites: A Review," in The Minerals, Metals E Materials Series: Springer International Publishing, 2019, pp. 3-18.

[21] G. Eddy Jai Poinern, S. Brundavanam, and D. Fawcett, "Biomedical Magnesium Alloys: A Review of Material Properties, Surface Modifications and Potential as a Biodegradable Orthopaedic Implant," American Journal of Biomedical Engineering, vol. 2, no. 6, pp. 218-240, 2013-01-07 2013, doi: 10.5923/j.ajbe.20120206.02.

[22] MEMSnet $\quad$ Material: Aluminum (Al), bulk." http://www.memsnet.org/material/aluminumalbulk/ (accessed 13 May 2021.

[23] J.R. Davis, Aluminum and Aluminum Alloys (Alloying: Understanding the Basics). ASM International, 2001.

[24] P. Chakraborty Banerjee, S. Al-Saadi, L. Choudhary, S. E. Harandi, and R. Singh, "Magnesium Implants: Prospects and Challenges," Materials, vol. 12, no. 1, 2019, doi: 10.3390/ma12010136.

[25] F. H. Silver and D. L. Christiansen, "Mechanical Properties of Tissues," in Biomaterials Science and Biocompatibility, F. H. Silver and D. L. Christiansen Eds. New York, NY: Springer New York, 1999, pp. 187-212.

[26] E. F. Morgan, G. U. Unnikrisnan, and A. I. Hussein, "Bone Mechanical Properties in Healthy and Diseased States," Annual Review of Biomedical Engineering, vol. 20, no. 1, pp. 119-143, 2018-06-04 2018, doi: 10.1146/annurev-bioeng-062117-121139.

[27] B. L. Mordike and T. Ebert, "Magnesium," Materials Science and Engineering: A, vol. 302, no. 1, pp. 37-45, 2001-04-01 2001, doi: 10.1016/s0921-5093(00)01351-4.

[28] A. A. Luo, "Applications: aerospace, automotive and other structural applications of magnesium," in Fundamentals of Magnesium Alloy Metallurgy: Elsevier, 2013, pp. 266-316.

[29] U. Riaz, I. Shabib, and W. Haider, "The current trends of Mg alloys in biomedical applications - A review," Journal of Biomedical Materials Research Part B: Applied Biomaterials, vol. 107, no. 6, pp. 1970-1996, 2019-08-01 2019, doi: 10.1002/jbm.b.34290.

[30] D. Zhao, F. Witte, F. Lu, J. Wang, J. Li, and L. Qin, "Current status on clinical applications of magnesium-based orthopaedic implants: A review from clinical translational perspective," Biomaterials, vol. 112, pp. 287-302, 2017-01-01 2017, doi: 10.1016/j.biomaterials.2016.10.017. 
[31] S. Kamrani and C. Fleck, "Biodegradable magnesium alloys as temporary orthopaedic implants: a review," BioMetals, vol. 32, no. 2, pp. 185-193, 2019-04-01 2019, doi: 10.1007/s10534-019-00170-y.

[32] F. Witte, N. Hort, F. Feyerabend, and C. Vogt, "Magnesium (Mg) corrosion: a challenging concept for degradable implants," in Corrosion of Magnesium Alloys: Elsevier, 2011, pp. 403-425.

[33] G. Song, "Control of biodegradation of biocompatable magnesium alloys," Corrosion Science, vol. 49, no. 4, pp. 1696-1701, 2007-04-01 2007, doi: 10.1016/j.corsci.2007.01.001.

[34] S. Agarwal, J. Curtin, B. Duffy, and S. Jaiswal, "Biodegradable magnesium alloys for orthopaedic applications: A review on corrosion, biocompatibility and surface modifications," Materials Science and Engineering: C, vol. 68, pp. 948-963, 2016-11-01 2016, doi: 10.1016/j.msec.2016.06.020.

[35] R.-C. Zeng, Z.-Z. Yin, X.-B. Chen, and D.-K. Xu, "Corrosion Types of Magnesium Alloys," in Magnesium Alloys - Selected Issue: IntechOpen, 2018.

[36] G. Song, A. Atrens, and D. Stjohn, "An Hydrogen Evolution Method for the Estimation of the Corrosion Rate of Magnesium Alloys," in Essential Readings in Magnesium Technology: Springer International Publishing, 2016, pp. 565-572.

[37] Y. Tang, L. Zhu, P. Zhang, K. Zhao, and Z. Wu, "Enhanced corrosion resistance of bio-piezoelectric composite coatings on medical magnesium alloys," Corrosion Science, vol. 176, p. 108939, 2020-11-01 2020, doi: 10.1016/j.corsci.2020.108939.

[38] H. M. Mousa, H. P. Chan, and C. S. Kim, "Surface Modification of Magnesium and its Alloys Using Anodization for Orthopedic Implant Application," in Magnesium Alloys: InTech, 2017.

[39] T. S. N. S. Narayanan, I.-S. Park, and M.-H. Lee, "Surface modification of magnesium and its alloys for biomedical applications," in Surface Modification of Magnesium and its Alloys for Biomedical Applications: Elsevier, 2015, pp. $29-87$.

[40] Y. Shao et al., "Advance in Antibacterial Magnesium Alloys and Surface Coatings on Magnesium Alloys: A Review," Acta Metallurgica Sinica (English Letters), vol. 33, no. 5, pp. 615-629, 2020-05-01 2020, doi: 10.1007/s40195-020-01044-w.

[41] W. Ahmed, Z. Zhai, and C. Gao, "Adaptive antibacterial biomaterial surfaces and their applications," Materials Today Bio, vol. 2, p. 100017, 2019-03-01 2019, doi: 10.1016/j.mtbio.2019.100017.

[42] H. Feng et al., "Systematic Study of Inherent Antibacterial Properties of Magnesium-based Biomaterials," ACS Applied Materials $\mathcal{E}$ Interfaces, vol. 8, no. 15, pp. 9662-9673, 2016-04-20 2016, doi: 10.1021/acsami.6b02241.

[43] J. Rodríguez-Sánchez, M. Á. Pacha-Olivenza, and M. L. González-Martín, "Bactericidal effect of magnesium ions over planktonic and sessile Staphylococcus epidermidis and Escherichia coli," Materials Chemistry and Physics, vol. 221, pp. 342348, 2019-01-01 2019, doi: 10.1016/j.matchemphys.2018.09.050.

[44] C. Liu, Z. Ren, Y. Xu, S. Pang, X. Zhao, and Y. Zhao, "Biodegradable Magnesium Alloys Developed as Bone Repair Materials: A Review," Scanning, vol. 2018, pp. 1-15, 2018-01-01 2018, doi: 10.1155/2018/9216314.

[45] T. Schilling, M. Bauer, L. Lalonde, H. J. Maier, A. Haverich, and T. Hassel, "Cardiovascular Applications of Magnesium Alloys," in Magnesium Alloys: InTech, 2017.

[46] K. Sangeetha, A. V. Jisha Kumari, J. Venkatesan, A. Sukumaran, S. Aisverya, and P. N. Sudha, "Degradable metallic biomaterials for cardiovascular applications," in Fundamental Biomaterials: Metals: Elsevier, 2018, pp. 285-298.

[47] J. Fu, Y. Su, Y.-X. Qin, Y. Zheng, Y. Wang, and D. Zhu, "Evolution of metallic cardiovascular stent materials: A comparative study among stainless steel, magnesium and zinc," Biomaterials, vol. 230, p. 119641, 2020-02-01 2020, doi: 10.1016/j.biomaterials.2019.119641.

[48] ReportLinker, "Global Magnesium Industry," Global Industry Analysis 5799036, July 2020 2020. Accessed: 10 Oct 2020.

[49] U.S. Geological Survey. (2020). Mineral Commodity Summaries (Magnesium Metals).

[50] F. Gao, Z.-R. Nie, Z.-H. Wang, X.-Z. Gong, and T.-Y. Zuo, "Assessing environmental impact of magnesium production using Pidgeon process in China," Transactions of Nonferrous Metals Society of China, vol. 18, no. 3, pp. 749-754, 2008-06-01 2008, doi: 10.1016/s1003-6326(08)60129-6.

[51] S. Ramakrishnan and P. Koltun, "Global warming impact of the magnesium produced in China using the Pidgeon process," Resources, Conservation and Recycling, vol. 42, no. 1, pp. 49-64, 2004-08-01 2004, doi: 10.1016/j.resconrec.2004.02.003. 
[52] G. Brooks, S. Trang, P. Witt, M. N. H. Khan, and M. Nagle, "The carbothermic route to magnesium," JOM, vol. 58, no. 5, pp. 51-55, 2006-05-01 2006, doi: 10.1007/s11837-006-0024-x.

[53] H. Abedini Najafabadi, N. Ozalp, M. Epstein, and R. Davis, "Solar Carbothermic Reduction of Dolime as a Promising Option To Produce Magnesium and Calcium," Industrial \& Engineering Chemistry Research, vol. 58, no. 51, pp. 23540-23548, 2019-1226 2019, doi: 10.1021/acs.iecr.9b04856.

[54] Y. Wang et al., "Challenges and Solutions for the Additive Manufacturing of Biodegradable Magnesium Implants," Engineering, 2020-08-01 2020, doi: 10.1016/j.eng.2020.02.015.

[55] R. Karunakaran, S. Ortgies, A. Tamayol, F. Bobaru, and M. P. Sealy, "Additive manufacturing of magnesium alloys," Bioactive Materials, vol. 5, no. 1, pp. 44-54, 2020-03-01 2020, doi: 10.1016/j.bioactmat.2019.12.004.

[56] Y. Qin et al., "Additive manufacturing of biodegradable metals: Current research status and future perspectives," Acta Biomaterialia, vol. 98, pp. 3-22, 2019-10-01 2019, doi: 10.1016/j.actbio.2019.04.046.

[57] J. P. Davim, Additive and Subtractive Manufacturing: Emergent Technologies. De Gruyter, 2020.

[58] International Magnesium Association. "Recycling Magnesium." https://www.intlmag.org/page/sustain recycle ima (accessed 10 Oct 2020.

[59] S. Ehrenberger and H. E. Friedrich, "Life-Cycle Assessment of the Recycling of Magnesium Vehicle Components," JOM, vol. 65, no. 10, pp. 1303-1309, 2013-10-01 2013, doi: 10.1007/s11837-013-0703-3.

[60] C. L. Mendis and A. Singh, "Magnesium Recycling: To the Grave and Beyond," JOM, vol. 65, no. 10, pp. 1283-1284, 2013-1001 2013, doi: 10.1007/s11837-013-0701-5. 